\title{
Butabarbital Measurement
}

National Cancer Institute

\section{Source}

National Cancer Institute. Butabarbital Measurement. NCI Thesaurus. Code C75364.

The determination of the amount of butabarbital present in a sample. 